\title{
How to build a lung: latest advances and emerging themes in lung bioengineering
}

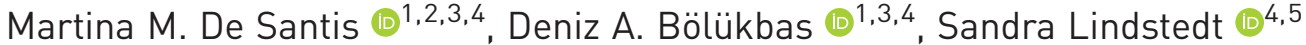 \\ and Darcy E. Wagner (1) $1,2,3,4$
}

Affiliations: ${ }^{1}$ Lung Bioengineering and Regeneration, Dept of Experimental Medical Sciences, Lund University, Lund, Sweden. ${ }^{2}$ Lung Repair and Regeneration (LRR), Comprehensive Pneumology Center (CPC), Helmholtz Zentrum Munich, Member of the German Center for Lung Research (DZL), Munich, Germany. ${ }^{3}$ Stem Cell Centre, Lund University, Lund, Sweden. "Wallenberg Center for Molecular Medicine, Lund University, Lund, Sweden. ${ }^{5}$ Dept of Cardiothoracic Surgery, Heart and Lung Transplantation, Lund University Hospital, Lund, Sweden.

Correspondence: Darcy E. Wagner, Dept of Experimental Medical Sciences, C12 BMC, Lund University, Sölvegatan 19, 22184 Lund, Sweden. E-mail: darcy.wagnerdamed.lu.se

@ERSpublications

Bioengineering lung tissue shows promise but major challenges must be overcome to advance technologies to the clinic http://ow.ly/T9cU30ko0BS

Cite this article as: De Santis MM, Bölükbas DA, Lindstedt S, et al. How to build a lung: latest advances and emerging themes in lung bioengineering. Eur Respir J 2018; 52: 1601355 [https://doi.org/10.1183/ 13993003.01355-2016].

ABSTRACT Chronic respiratory diseases remain a major cause of morbidity and mortality worldwide. The only option at end-stage disease is lung transplantation, but there are not enough donor lungs to meet clinical demand. Alternative options to increase tissue availability for lung transplantation are urgently required to close the gap on this unmet clinical need. A growing number of tissue engineering approaches are exploring the potential to generate lung tissue ex vivo for transplantation. Both biologically derived and manufactured scaffolds seeded with cells and grown ex vivo have been explored in pre-clinical studies, with the eventual goal of generating functional pulmonary tissue for transplantation. Recently, there have been significant efforts to scale-up cell culture methods to generate adequate cell numbers for human-scale bioengineering approaches. Concomitantly, there have been exciting efforts in designing bioreactors that allow for appropriate cell seeding and development of functional lung tissue over time. This review aims to present the current state-of-the-art progress for each of these areas and to discuss promising new ideas within the field of lung bioengineering. 


\section{Introduction}

\section{Background}

Respiratory diseases are the third leading cause of death worldwide and are predicted to continue to increase over the coming years. The overall cost of respiratory disease in the European Union amounts to more than EUR380 billion annually [1]. Currently, the only option for end-stage respiratory disease is lung transplantation. Approximately 2000 lung transplants occur annually in Europe [2], with the same number or more patients awaiting transplantation. Transplant efficacy remains a significant clinical issue as transplant rejection rates are high and complications can arise due to the required immunosuppressive drugs; 5-year survival is only 50\% [3]. Alternative options to increase available tissue for lung transplantation are necessary to close the gap on this unmet clinical need. In addition to the use of lungs donated from circulatory death (DCD) donors, and continued development and improvements in ex vivo preservation and ex vivo lung perfusion (EVLP) techniques attempting to maximise the number of donor lungs suitable for transplantation [4-9], an exciting new area of research focuses on generating lung tissue ex vivo.

\section{Novel ideas and hypothesis}

The lung is a highly complex and dynamic organ comprised of a number of different cell types with distinct functions [10]. Bioengineering lung tissue ex vivo for transplantation is an area receiving increased attention and could address the shortage of donor organs. Current approaches being explored in pre-clinical studies utilise biologically derived or synthetic scaffolds that are seeded with autologous cells from the eventual transplant recipient. Both synthetic and biologically derived scaffolds have distinct advantages and disadvantages. Hybrid scaffolds combining biologically derived and synthetic scaffolds may be a novel approach to limit the disadvantages observed with either synthetic or biologically derived scaffolds alone. Various different technologies have been developed to help generate tissue engineering scaffolds for lung, such as decellularisation for biological scaffolds, and advanced manufacturing processes for producing synthetic scaffolds, such as casting, electrospinning, cryogelation and microfabrication techniques.

Thus, bioengineered lung tissue could help to increase the amount of lung tissue available for transplantation and has the potential to offer benefits over allogeneic transplantation. In this review, we aim to discuss recent advances and emerging themes in lung tissue engineering, and the major challenges that need to be overcome to advance this approach closer to the clinic.

\section{Manufacturing lung scaffolds}

The lung has at least 40 different resident cell types [10], all of which are necessary for optimal functioning. These cells reside on and within an extracellular matrix (ECM) comprised of different regional combinations of ECM proteins and glycosaminoglycans (e.g. proteoglycans and hyaluronan) that act together as a scaffold to not only provide structure, but also to help direct repair and regeneration following injury [11]. LANGER and VACANTI [12] first described tissue engineering approaches, whereby cells are combined with a matrix made of natural or synthetic materials and grown ex vivo, followed by transplantation (figure 1). Several case reports and clinical trials of tissue-engineered products have since demonstrated the feasibility of pursuing these technologies in the clinic [13, 14]. Although there were no attempts at generating pulmonary tissue ex vivo when tissue engineering was first described, most current approaches have adopted this paradigm. Despite the fact that lung tissue engineering approaches have historically lagged behind those of other fields, there have been exciting recent advances with both natural materials and synthetic materials.

\section{Acellular lung scaffolds \\ Scaffold source and effects of processing, storage and sterilisation}

Acellular (biological) lung scaffolds have emerged as possible scaffold materials for ex vivo lung tissue engineering in recent years. In this approach, acellular scaffolds are obtained by removing the cells from native lung tissue via a method called decellularisation. Ultimately, the goal of any decellularisation protocol is to remove the cellular material without adversely affecting the resulting macroscopic acellular scaffold structure and ECM composition, mechanical integrity or biological activity of the ECM components [15-17]. The acellular lung could then ideally be recellularised with autologous cells or, alternatively, an allogeneic source. A major advantage of acellular lung scaffolds is that they mostly retain the complex structure and macro- and micro-architecture of the native lung tissue, which cannot be generated using any known manufacturing techniques. The majority of ECM components have been found to be retained in the acellular tissue following decellularisation [18-20], although the degree to which these components are retained in their native orientation has not been studied extensively. The retention of ECM components, as well as their organisation, is probably vital for the function of the eventual engineered tissue. 


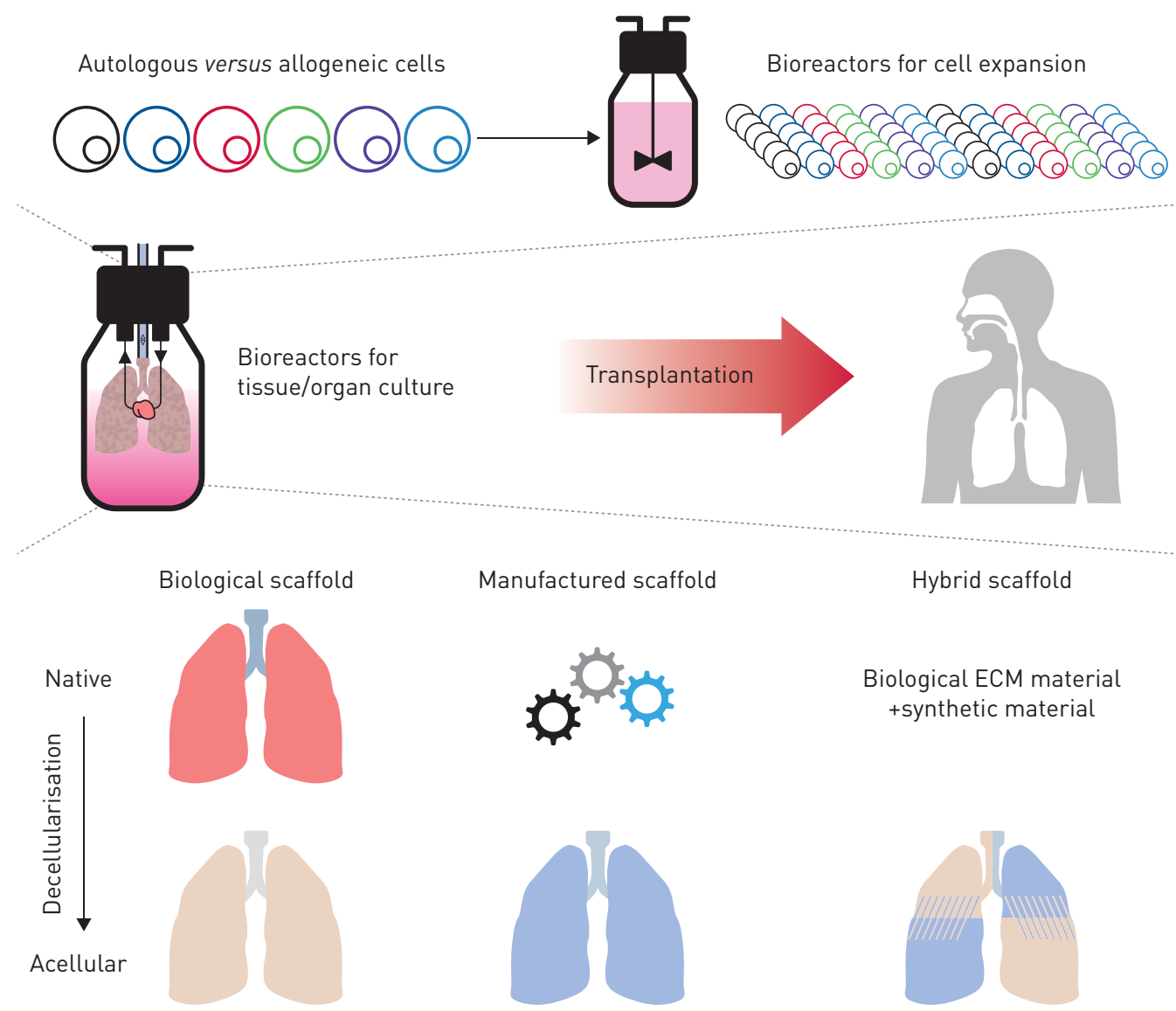

FIGURE 1 Lung bioengineering approaches. In most approaches, a lung scaffold is seeded with autologous or allogeneic cells for bioengineering a lung. The cells can be expanded to appropriate numbers in bioreactors for cell expansion. Different lung scaffolds have been explored, including decellularised scaffolds and synthetic scaffolds. An emerging idea is the use of hybrid scaffolds that combine biological materials such as extracellular matrix (ECM) components with synthetic scaffolds in order to create a hybrid lung scaffold. Bioreactors for organ culture can then be used to mature and evaluate the repopulated lung scaffold before lung transplantation.

The ECM is one of the major constituents of the microenvironment known to direct cell behaviour such as migration, proliferation and differentiation $[18,21,22]$. Acellular tissue scaffolds have been shown to retain bioactive properties and a certain degree of tissue specificity [19, 23]. Recent studies have shown that aged scaffolds and those derived from lung disease can drive the acquisition of deranged cellular phenotypes in cells from normal patients [21, 24-27]. Thus, human scaffolds from aged patients or those with pre-existing lung diseases are likely not the ideal sources for lung tissue engineering scaffolds.

Interestingly, a recent study indicated that scaffolds derived from early post-natal human lungs support enhanced re-epithelialisation compared with those derived from adult lungs [28]. Although post-natal lungs could be used to generate scaffolds for neonates, a major concern with using neonate lungs for adult lung tissue engineering is the size mismatch. A study that investigated the outcome of lung transplantation from size-mismatched donors and recipients found that undersized lungs received higher tidal volumes because of differences between the weight of donors and recipients [29, 30]. Additionally, lung transplants using undersized lungs are associated with an increased risk of primary graft dysfunction [31]. Although it is unclear how or if lungs from neonates might be used for adult lung tissue engineering schemes, the information gained from these studies may lead to new ideas for utilising scaffolds derived from adult donors.

When considering sources for clinical-grade scaffold materials, the donor tissue does not necessarily need to be of human origin. Lungs from anatomically similar species, such as porcine or nonhuman primates, may potentially provide a more uniform donor source, with less limitations than human sources $[19,25$, 32-35]. The use of nonhuman primate lungs has been restricted to pre-clinical models of bioengineering and there are ethical concerns with using nonhuman primates as a source of acellular scaffolds. Thus, porcine lungs have first emerged as a potential option due to the use of other porcine tissues in 
xenotransplantation. However, several species- and tissue-specific properties have been identified to date in porcine lungs that may prove challenging for translation of xenogeneic lung scaffolds recellularised with human cells. Pleural blebs (cystic spaces) have been shown by us and others to arise during the decellularisation process, which may affect the ventilation mechanics of the lung, ultimately compromising the function of the lung if transplanted $[24,33]$ and if ruptured would lead to pneumothorax (collapsed lung). Furthermore, the extent to which porcine lungs have collateral ventilation is limited compared with humans. Although a variety of cell types have been shown to adhere to porcine scaffolds $[24,25,33,35]$, human-derived endothelial cells were found to attach to porcine-derived scaffolds at a lower rate compared with human- or primate-derived scaffolds [36], but the reasons for this remain unknown. Residual, cell-associated xenogeneic proteins known to cause negative immunogenic responses in humans have been identified in scaffolds from porcine lungs that are decellularised according to current criteria [18, 25], thus indicating that removal of immunogenic proteins either through transgenic approaches or through post-decellularisation treatments might be necessary.

Moreover, there are several studies from human cohorts of transplantation that indicate the importance of size matching between donor and recipient [37]. In the case of porcine lungs, the airways and vasculature are often smaller than in human lungs. Surgically anastomosing a porcine lung to a human recipient, especially with regard to the bronchus, will be challenging and a donor-recipient mismatch is likely to occur that can lead to death. The lower pulmonary lobes of porcine lungs are shaped after the pig's body because it is a quadruped. The lower pulmonary lobes have a pointed shape and the lung ligaments are significantly more pronounced than in humans. Therefore, basal atelectasis of the lower lobes of the lung may occur if the lung is transplanted to a human and hence there is an increased risk of infection. The lower pulmonary lobes could be resected at the time of transplantation, but it is unclear if this would be optimal. Some transplant centres carry out lung resections at the time of transplantation to make the lung fit better into the thoracic cavity. However, some transplant centres are negative towards this approach because of the risk of air leakage from the lung post-operatively. In addition to the major anatomical differences, the risk of cross-species transmission of porcine endogenous retroviruses has impeded the clinical application of xenogeneic tissues [38]. To date, there has been no formal study of the removal or retention of zoonoses, including porcine endogenous retroviruses, in xenogeneic decellularised scaffolds and thus the danger of disease transmission across species remains unknown [36]. Therefore, adult human lungs that narrowly miss the criteria for transplantation and cannot be improved using EVLP technology $[6,7,39-41]$ may be viewed as the most likely candidates as a source of scaffolds for a clinical-grade lung tissue engineering scheme.

Storage and sterilisation of potential acellular scaffolds for lung tissue engineering have been found to significantly impact both the structure and residual protein content. Moreover, the ability of different cell types to survive and proliferate following inoculation has also been shown to be influenced by the conditions of storage and sterilisation of acellular scaffolds [42]. To date, the majority of acellular lungs have been sterilised using peracetic acid; however, this can result in ECM degradation [43, 44]. A recent report described the use of supercritical carbon dioxide for sterilising acellular lung scaffolds that does not induce degradation of the ECM [45]. Excellent progress has been made in techniques that could be compatible with Good Manufacturing Practice (GMP) [46]. Interestingly, despite the establishment of some baseline criteria, commercially available scaffolds for other tissues from different companies can have different responses in the same model of in vivo injury [47]. It is clear that defining optimal criteria and end-points regarding the scaffold source and processing of acellular scaffolds will be important in future studies (see table 1 for a summary of the challenges within the field of ex vivo lung tissue engineering).

\section{Decellularisation techniques}

Common methods to decellularise lungs include different combinations of physical, ionic, chemical and enzymatic methods [15]. Detergent-based perfusion has been most prevalently utilised to generate acellular lung scaffolds. Commonly used detergents include Triton X-100, sodium deoxycholate, sodium dodecylsulfate and CHAPS (3-((3-cholamidopropyl)dimethylammonio)-1-propanesulfonate), which are used with or without hypertonic sodium chloride and DNase and/or RNase solutions. The concentration and volume of detergents used varies between different protocols and species $[21,23,24,26,33,34,36$, 48-51]. Solutions may be perfused through the vasculature or both the airways and vasculature. The variation between different protocols has resulted in apparent histological differences of the decellularised lungs and in the content of both ECM and other retained proteins [50, 52, 53]. It remains unclear how differences in lung decellularisation protocols might affect recellularisation and regeneration or potential immunogenicity of the implanted scaffold [54, 55]. The majority of laboratories decellularising tissue utilise the criteria set forth by CRAPO et al. [18], which include absence of visible cellular or nuclear material on histological examination, $<50 \mathrm{ng}$ double-stranded DNA per $1 \mathrm{mg}$ of dry 
TABLE 1 Challenges within the field of ex vivo lung tissue engineering

\begin{tabular}{|c|c|}
\hline Area & Focus for future research/future perspectives \\
\hline \multirow[t]{4}{*}{ Scaffold source } & Can a suitable acellular xenograft source be identified? \\
\hline & Can allogeneic human scaffolds be used? \\
\hline & Does the age (neonatal or aged) of the scaffold impact the biomaterial? \\
\hline & Evaluate immunogenicity of scaffold with and without cells. \\
\hline \multirow[t]{4}{*}{ Cell sources } & $\begin{array}{l}\text { Are all of the more than } 40 \text { cell types found within the lung required to make a } \\
\text { functional lung? }\end{array}$ \\
\hline & Can allogeneic cells be used or do we need to use autologous cells? \\
\hline & Where will we source cells for patients with chronic or genetic lung diseases? \\
\hline & $\begin{array}{l}\text { What types of cell sources can be used (e.g. endogenous progenitor cells, } \\
\text { induced pluripotent stem cells)? }\end{array}$ \\
\hline \multirow[t]{4}{*}{ Manufacturing } & $\begin{array}{l}\text { Which Good Manufacturing Practice manufacturing method will be suitable for } \\
\text { scaffold generation, storage and maturation? }\end{array}$ \\
\hline & $\begin{array}{l}\text { Which standardised approaches for the characterisation and validation of the } \\
\text { scaffold will be required? }\end{array}$ \\
\hline & $\begin{array}{l}\text { How can we obtain enough cells to recellularise and how will they be } \\
\text { re-introduced into the scaffold? }\end{array}$ \\
\hline & $\begin{array}{l}\text { Will bioengineered lungs need to be tailored for patients with specific lung } \\
\text { diseases (e.g. the main lung transplant recipients (chronic obstructive } \\
\text { pulmonary disease, idiopathic pulmonary fibrosis, pulmonary arterial } \\
\text { hypertension, cystic fibrosis and } \alpha_{1} \text {-antitrypsin deficiency)). }\end{array}$ \\
\hline \multirow[t]{3}{*}{ Maturation } & Will different bioreactors be needed for the different cell types in the lung? \\
\hline & What time span and/or maturation level will be required? \\
\hline & What degree of vascularisation of the scaffold will be required? \\
\hline \multirow{5}{*}{$\begin{array}{l}\text { Surgical and clinical } \\
\text { approach }\end{array}$} & How will we assess the functionality prior to transplantation? \\
\hline & Will ex vivo lung perfusion parameters be enough to predict success? \\
\hline & $\begin{array}{l}\text { What surgical techniques could be used for pieces of bioengineered lung } \\
\text { tissue? }\end{array}$ \\
\hline & Will special post-operative care be required? \\
\hline & Will the patients need to be immunosuppressed? \\
\hline
\end{tabular}

weight of the ECM scaffold and remnant DNA $<200$ bp. However, these are minimum criteria that do not take into account cytocompatibility (e.g. effects of residual decellularising agents), sterility, composition and mechanical properties of the acellular scaffold [56, 57]. ECM composition and mechanical properties are regionally specific, and retention of these differences may be important for recellularisation leading to functional tissue.

Recellularisation and pre-clinical transplantation models

A variety of different cell types have been successfully used in recellularisation of acellular scaffolds, including embryonic stem cells (ESCs), induced pluripotent stem cells (iPSCs) and endogenous lung progenitor cells. Efficient differentiation of pluripotent cells to proximal and distal lung epithelial cells remains a challenging task, but there has been exciting recent progress in deriving distal epithelial progenitor cells and multilayered epithelium from iPSCs and murine ESCs [50, 51, 58-65].

Differentiation of pluripotent stem cells into proximal or distal lung epithelial cells requires growth factors known to be sequestered by the lung ECM [66]. Thus, retention of ECM components and their associated growth factors in decellularised lung scaffolds may be critical for optimal recellularisation with regional specificity. The ability of the reseeded cells to survive, proliferate and differentiate is important for assessing both short- and long-term cytocompatibility of the scaffold. Further understanding of how the remaining ECM and residual protein composition may affect seeded cell types over time will be an important area of future studies (table 1).

Important proof-of-concept studies have shown that acellular lung scaffolds can be recellularised with either single-cell suspensions from fetal lung homogenates and re-endothelialised with immortalised endothelial cell lines or iPSC-derived endothelium and epithelium [67] for transplantation. When transplanted into rats, recellularised lung scaffolds were shown to briefly function in vivo $[48,51,68,69]$ and, more recently, acellular porcine scaffolds recellularised with human cells in scaled-up porcine studies [35]. However, transplanted lungs were oedematous with regions of collapsed architecture, indicating that long-term functional lung regeneration has yet to be achieved. Nonetheless, these studies encourage the feasibility of this approach. 


\section{The Goldilocks Principle of the remaining proteins: "too much", "too little" and finding} "just right"

The purpose of most decellularisation processes is to remove the cellular and immunogenic material from the scaffold, while retaining the ECM proteins and structure. However, as mass spectrometry proteomics have rapidly improved to characterise the composition of acellular scaffolds, it has become increasingly evident that large amounts of non-matrisome proteins (cytoskeletal elements and cell-associated proteins) are retained in the scaffold following decellularisation [21, 24]. The presence of non-matrisome proteins has been observed across different tissues, species and techniques used in different laboratories [50, 64, 70]. The impact of these residual proteins and other cell-derived components on reseeded cells and their potential immunogenicity have been relatively unexplored for lung tissue engineering. It remains unclear if 1) decellularisation protocols that are more aggressive and remove more components or 2) protocols that are less aggressive but retain more components will be more beneficial in supporting functional regeneration. Residual proteins have been shown to play a significant role in other tissues in regulating cell behaviour of reseeded cells and on immune cell infiltrates once implanted [71]. Furthermore, the clinical heterogeneity observed between individual healthy patients may make defining minimum criteria challenging [24]. Ultimately, improving our understanding of the composition of decellularised scaffolds and tying these to biological outcomes is an important future direction for the field.

Table 2 and the following sections summarise some of the most important studies to date that have led to advances inusing acellular scaffolds for lung tissue engineering $[22,24,25,33,34,42,48,49,51,52,59$, $64,65,72-128]$.

\section{Artificial lung scaffolds}

Although acellular scaffolds show promise in the field of lung bioengineering, the heterogeneity of human lung-derived acellular scaffolds and potential xenogeneic issues make this approach challenging to scale-up in a reproducible and controllable manner [21]. An alternative to acellular scaffolds could be artificial (or manufactured) scaffolds. Both synthetic and natural polymers can be used in these approaches, and a variety of materials have already been explored for tracheal, bronchial and parenchymal lung tissue engineering (figure 2 and table 2). Artificial scaffolds for tracheas have been more intensively investigated due to the trachea's simpler, tubular structure [72-78]. Many of the materials used to generate scaffolds for pre-clinical studies for large airways are synthetic polymers such as POSS-PCU (polyhedral oligomeric silsesquioxane poly(carbonate-urea) urethane) [72], polyglycolic acid, pluronic F-127 [79] and polylactic-co-glycolic acid [80], which are all cytocompatible polymers with mechanical properties in the range needed for tracheal tissue engineering. Although these materials can be manufactured with good precision and can be processed to have improved storage stability, most lack the necessary biological properties, such as native integrin binding sites and bioactive cues for cellular attachment, proliferation and differentiation. It is currently unknown what motifs will need to be added to these scaffolds to support functional regeneration. However, it has been shown that cell seeding and graft coverage can be enhanced by simply modifying the surface of the polymer used in the scaffold, e.g. providing cell attachment sites by increasing surface porosity [72] and/or incorporating individual ECM components [73].

On the contrary, parenchymal lung tissue has a more complex three-dimensional (3D) structure, and requires thin boundaries and interconnected pores for efficient gas exchange [81]. Due to the difficulty associated with manufacturing a scaffold with geometrical parameters suitable for parenchymal lung tissue, there have been limited reports. To date, potential scaffolds for parenchymal tissue engineering have been fabricated via foaming [82, 83], porogen-solvent techniques, cryogelation [84], photodegradation [85, 86] and self-assembly of microspheres [87]. Although these techniques are able to recapitulate alveolar-like structures, they lack the vasculature and airways required for integration into recipients, and ultimately for gas exchange. However, a recent report showed that a 3D gelatine microbubble scaffold seeded with murine pluripotent stem cells promoted angiogenesis when implanted [82]. Thus, if these constructs could somehow be hooked up to an air supply and the boundaries of the blood-air barrier were thin enough, it is conceivable that these constructs could support gas exchange. Although important as proof-of-concept studies, none of these subtractive or bulk manufacturing techniques have been successful in generating functional lung tissue and incorporation of vasculature has not yet been explored. Synthetic materials could be of immense value for generating lung scaffolds due to the ability to precisely and reproducibly manufacture them for individual patients, but suitable manufacturing methods are not yet known. However, there are approaches that have been used in other organs that may be worthwhile exploring for lung tissue which will be discussed in the following section.

Potential manufacturing methods to generate porous scaffolds for lung tissue engineering From a simplistic viewpoint, the lung parenchyma is a system of interconnected porous-like structures surrounded by a capillary bed to facilitate gas exchange [81]. There are several different 
TABLE 2 Compilation of studies of breakthrough advances within the field of ex vivo lung tissue engineering

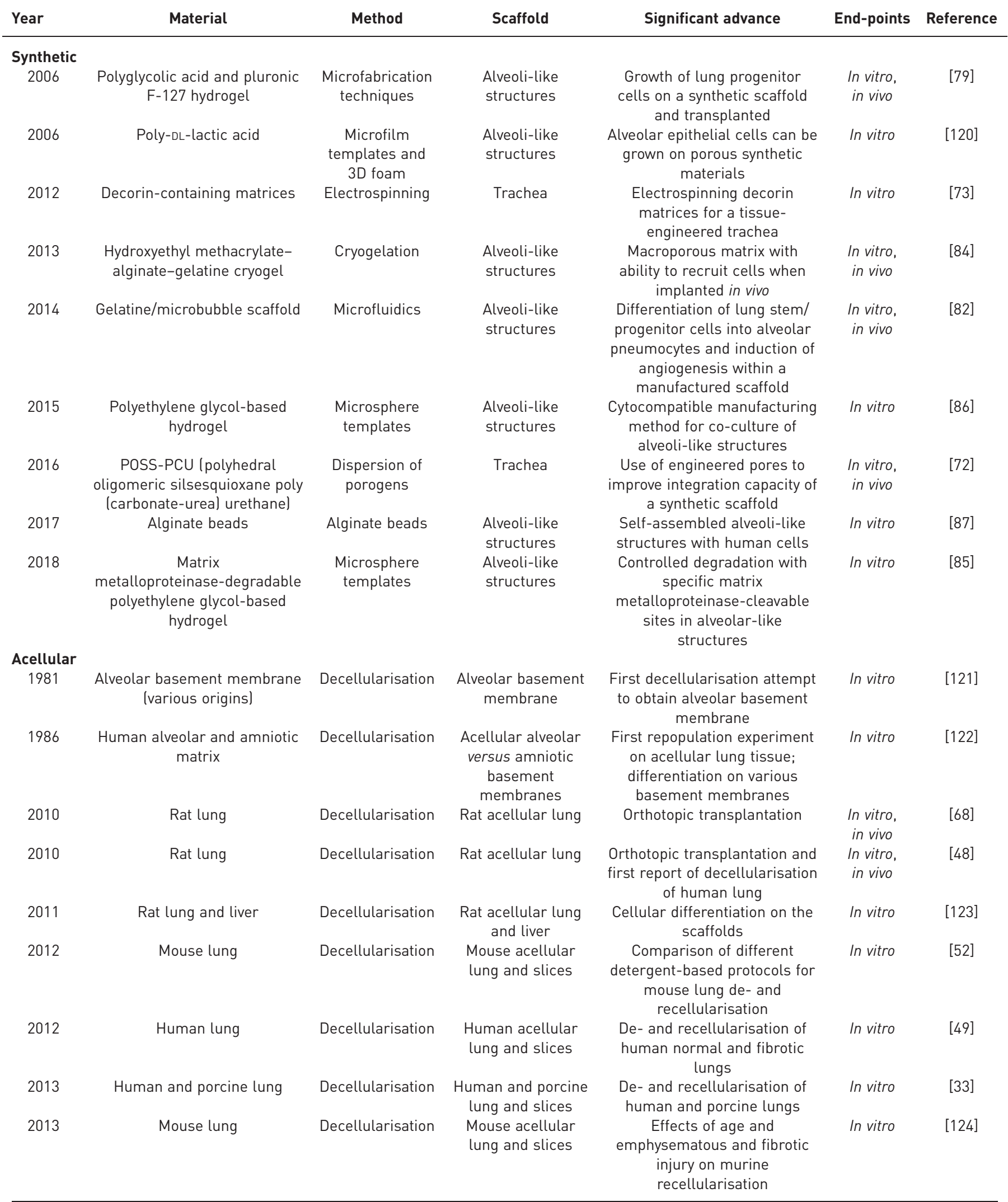


TABLE 2 Continued

\begin{tabular}{|c|c|c|c|c|c|c|}
\hline Year & Material & Method & Scaffold & Significant advance & End-points & Reference \\
\hline 2014 & Human and porcine lung & Decellularisation & 3D lung segments & $\begin{array}{l}\text { Small segments to retain } 3 D \\
\text { lung structure in acellular } \\
\text { scaffolds from large animals } \\
\text { and human origin for } \\
\text { physiological recellularisation }\end{array}$ & In vitro & [24] \\
\hline 2014 & Rat and human lung & Decellularisation & $\begin{array}{l}\text { Rat and human } \\
\text { acellular lung }\end{array}$ & $\begin{array}{l}\text { Transplant of iPSC-derived } \\
\text { re-epithelialised and } \\
\text { re-endothelialised scaffold }\end{array}$ & $\begin{array}{l}\text { In vitro, } \\
\text { in vivo }\end{array}$ & {$[51]$} \\
\hline 2015 & Rat and human lung & Decellularisation & $\begin{array}{l}\text { Rat and human } \\
\text { acellular lung }\end{array}$ & $\begin{array}{l}\text { Regeneration of functional } \\
\text { pulmonary vasculature }\end{array}$ & $\begin{array}{l}\text { In vitro, } \\
\text { in vivo }\end{array}$ & [65] \\
\hline 2016 & Porcine lung & Decellularisation & $\begin{array}{l}\text { Porcine lung } \\
\text { extracellular matrix } \\
\text { hydrogel }\end{array}$ & $\begin{array}{l}\text { First extracellular matrix } \\
\text { hydrogel derived from } \\
\text { acellular lung }\end{array}$ & $\begin{array}{l}\text { In vitro, } \\
\text { in vivo }\end{array}$ & [125] \\
\hline 2017 & Porcine lung & Decellularisation & Porcine lung & $\begin{array}{l}\text { Orthotopic transplantation of } \\
\text { porcine scaffold recellularised } \\
\text { with human cells }\end{array}$ & $\begin{array}{l}\text { In vitro, } \\
\text { in vivo }\end{array}$ & [35] \\
\hline \multicolumn{7}{|c|}{ 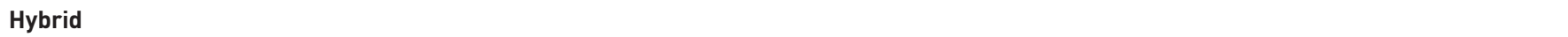 } \\
\hline 2006 & $\begin{array}{l}\text { Polylactic-co-glycolic acid, } \\
\text { poly-L-lactic acid and Matrigel } \\
\text { porous foam and nanofibrous } \\
\text { matrix }\end{array}$ & $\begin{array}{l}\text { Microfabrication } \\
\text { techniques }\end{array}$ & $\begin{array}{l}\text { Alveoli-like } \\
\text { structures }\end{array}$ & $\begin{array}{l}\text { First hybrid material attempt } \\
\text { for lung tissue engineering }\end{array}$ & In vitro & {$[80]$} \\
\hline 2008 & $\begin{array}{l}\text { Matrigel plug combined with } \\
\text { fibroblast growth factor 2- } \\
\text { loaded polyvinyl sponge }\end{array}$ & $\begin{array}{l}\text { Microfabrication } \\
\text { techniques }\end{array}$ & $\begin{array}{l}\text { Vascularised } \\
\text { pulmonary tissue } \\
\text { constructs }\end{array}$ & $\begin{array}{l}\text { Distal pulmonary epithelial } \\
\text { differentiation can be } \\
\text { maintained in vivo; } \\
\text { donor-derived endothelial } \\
\text { cells contribute to the } \\
\text { formation of vessels }\end{array}$ & $\begin{array}{l}\text { In vitro, } \\
\text { in vivo }\end{array}$ & [126] \\
\hline 2011 & $\begin{array}{l}\text { Collagen-Matrigel/alginate } \\
\text { microcapsules }\end{array}$ & $\begin{array}{l}\text { Microsphere } \\
\text { encapsulation }\end{array}$ & $\begin{array}{l}\text { Alveoli-like } \\
\text { structures }\end{array}$ & $\begin{array}{c}\text { Fibroblasts, epithelial cells } \\
\text { and alveolar type II form } \\
\text { alveolus-like structures in } \\
\text { collagen-Matrigel/ } \\
\text { alginate-poly-L-lysine-alginate } \\
\text { microcapsule engineered } \\
\text { scaffolds }\end{array}$ & In vitro & [127] \\
\hline 2017 & $\begin{array}{l}\text { Poly- } \varepsilon \text {-caprolactone and } \\
\text { decellularised aorta }\end{array}$ & $\begin{array}{l}\text { Electrospinning, } \\
\text { decellularisation }\end{array}$ & $\begin{array}{l}\text { Electrospun } \\
\text { poly- } \varepsilon \text {-caprolactone } \\
\text { stents in acellular } \\
\text { rabbit aorta }\end{array}$ & $\begin{array}{l}\text { Hybrid trachea scaffold for } \\
\text { tracheal replacement }\end{array}$ & $\begin{array}{l}\text { In vitro, } \\
\text { in vivo }\end{array}$ & [128] \\
\hline \multicolumn{7}{|l|}{ Cells } \\
\hline 2014 & Human pluripotent stem cells & NA & NA & $\begin{array}{l}\text { Functional human pluripotent } \\
\text { stem cell-derived distal lung } \\
\text { epithelial cells seeded onto } \\
\text { human scaffold }\end{array}$ & $\begin{array}{l}\text { In vitro, } \\
\text { in vivo }\end{array}$ & [59] \\
\hline 2015 & $\begin{array}{l}\text { Human endothelial and } \\
\text { perivascular cells }\end{array}$ & NA & NA & $\begin{array}{l}\text { Regeneration of functional } \\
\text { pulmonary vasculature }\end{array}$ & $\begin{array}{l}\text { In vitro, } \\
\text { in vivo }\end{array}$ & [65] \\
\hline 2016 & $\begin{array}{l}\text { Human respiratory epithelial } \\
\text { cells }\end{array}$ & NA & NA & Scalable cell culture system & $\begin{array}{l}\text { In vitro, } \\
\text { in vivo }\end{array}$ & [107] \\
\hline
\end{tabular}


TABLE 2 Continued

\begin{tabular}{ccccccc} 
Year & Material & Method & Scaffold & Significant advance & End-points & Reference \\
\hline 2016 & $\begin{array}{c}\text { KRT5 }{ }^{+} \text {TP63 } \\
\text { stem cells }\end{array}$ & NA & Recellularisation & In vitro & [64] \\
2018 & $\begin{array}{c}\text { Chondrocytes, endothelial cells } \\
\text { and mesenchymal stem cells }\end{array}$ & 3D bioprinting & None & $\begin{array}{c}\text { Scaffold-free manufacturing of } \\
\text { a rat trachea mimic }\end{array}$ & $\begin{array}{c}\text { In vitro, } \\
\text { in vivo }\end{array}$ & $\begin{array}{c}\text { [101] } \\
\text { ratial }\end{array}$ \\
\hline
\end{tabular}

3D: three-dimensional; iPSC: induced pluripotent stem cell; NA: not applicable.

manufacturing methods that have been used for tissue engineering porous structures for other organs, e.g. freeze-drying, foaming, solvent-casting and particulate-leaching techniques [88]. Manufacturing processes have also been developed for generating perfusable vascular channels in tissue-engineered constructs [89].

Electrospinning is an additive manufacturing technique that has emerged as an effective method of producing nanoscale fibres for use in multiple fields, including tissue engineering of blood vessels [90], skin [91] and trachea [73]. Both synthetic and natural polymers can be used for electrospinning to create porous scaffolds comprised of thin nanofibres that have been shown to be capable of supporting cell attachment, proliferation and differentiation. By controlling fibre parameters such as size, density, composition and orientation, fibrous structures that are similar to the ECM can be produced. Moreover, molecules such as growth factors or pharmaceuticals can be included in the scaffold to influence and direct regeneration of the tissue spatially or temporally. Electrospinning has already been used as an in vitro platform for studying the effects of fibrotic lung micro-environments on various cell types [22]. Overall, electrospinning is a promising technique, but has been limited to only creating an in vitro assay platform and has not yet been used for bioengineering lung tissue.

Techniques that are amenable to creating custom-made, reproducible, intricate 3D designs using cytocompatible materials would be ideal for tissue engineering. 3D printing, or bioprinting when cells are printed, has recently emerged as a potential source for bioengineering tissues or supporting structures [9298]. 3D printing has been applied clinically for the treatment of tracheobronchomalacia [99] and tracheal collapse with 3D printed patient-specific tracheal splints [100]. However, in these instances, the 3D printing technology was simply used for supporting structures and not for regenerating transplantable tissue in humans. 3D printing has been explored for tissue engineering of organs such as rat trachea using a scaffold-free approach [101], skin [102], cartilage [103], aortic valve conduits [104] and vascular tissue [105], but there are currently no published reports of attempts to $3 \mathrm{D}$ print lung tissue capable of gas exchange. 3D bioprinting of distal lung will be extremely challenging, as the gas exchange barrier is of the order of nanometres and nozzles used for printing cells need to be in the micrometre range. Thus, new 3D printing or manufacturing approaches need to be developed to overcome this limitation. However, 3D printing technologies are advanced enough for printing structures at the resolution of the trachea and bronchus (figure 2), but materials and manufacturing methods compatible with cells have not yet been reported.

One challenge in 3D printing of biological tissue is that many current techniques for printing high-resolution structures use processes that are incompatible with directly printing cells and many biological materials. Traditional 3D printing approaches rely on solvents or heating to generate polymer solutions that can flow as liquids through the $3 \mathrm{D}$ printing nozzles. Thus, these limitations have contributed to slow progress in $3 \mathrm{D}$ printing of lung and other tissues.

It is important that the material printed does not degrade before new ECM is synthesised, deposited and organised by seeded cells that can support the structure of the tissue and handle any mechanical loading (e.g. further cell seeding, bioreactor parameters and surgical handling) [106]. Thus, the degradation kinetics and the impact of the degradation products are important parameters to consider when selecting, designing and validating potential new biomaterials for pulmonary tissue engineering applications. These and other issues need to be addressed for successful application of manufactured scaffolds for generating lung or airway tissue.

\section{Hybrid materials}

Although both acellular scaffolds and manufactured scaffolds have shown progress, ultimately neither may be the optimal scaffold material alone. In many other manufacturing fields, optimal materials are derived through the use of hybrid or composite materials whereby the positive attributes of two or more materials can be combined to generate a final material with optimal overall properties that overcome the limitations of the individual constituent components. Using hybrid or composite materials to manufacture scaffolds 

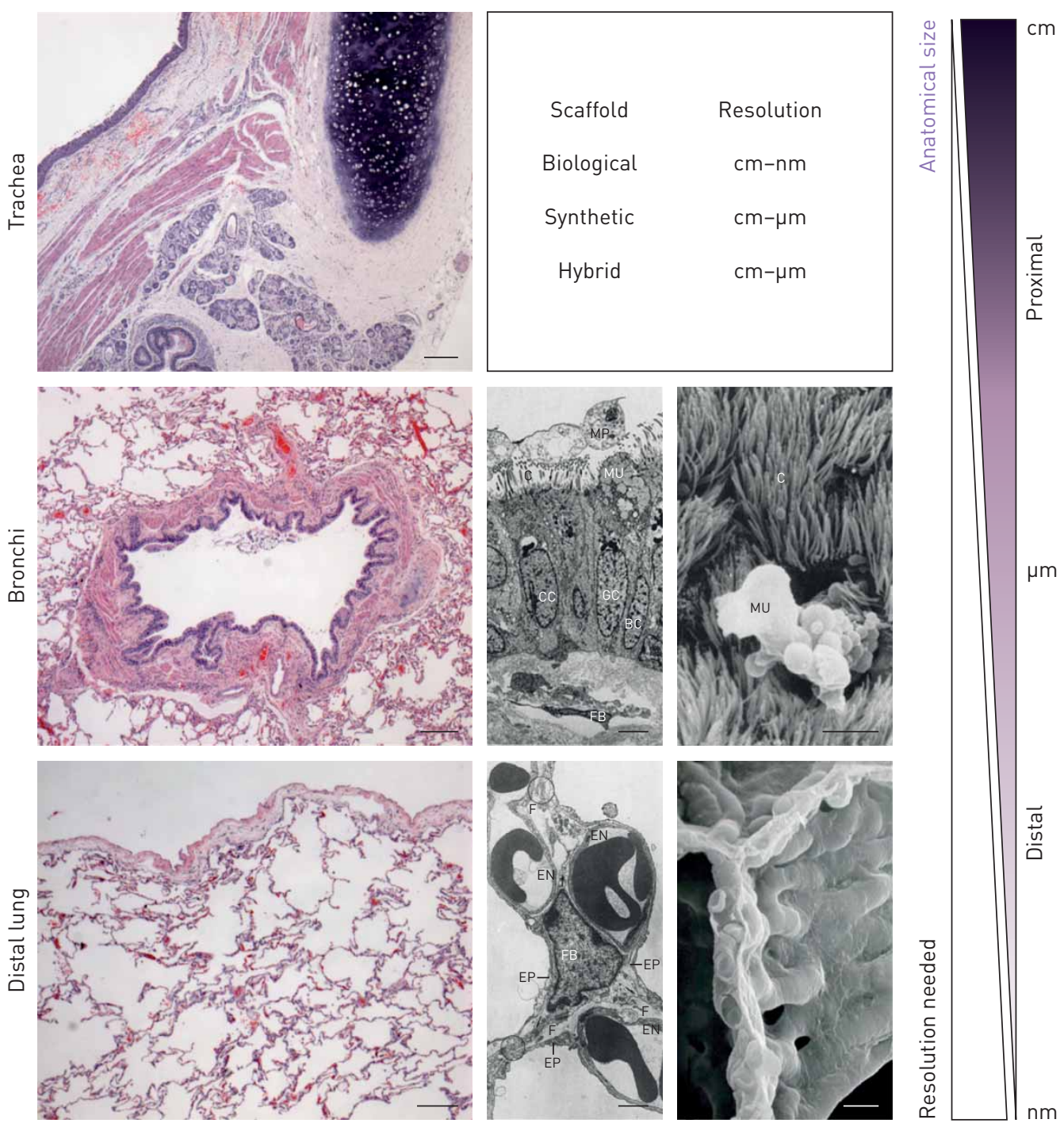

FIGURE 2 Recapitulating the complexity of the lung architecture from proximal (trachea) to distal (bronchi and alveoli): haematoxylin/eosin (HE; left column) staining histology, transmission electron microscopy (TEM; centre column) and scanning electron microscopy (SEM; right column) images from proximal and distal native lung tissue. The lung architecture varies dramatically within the lung: moving from proximal to distal, the resolution required to mimic the native structures is higher (centimetres $(\mathrm{cm}) \rightarrow$ micrometres $(\mu \mathrm{m}) \rightarrow$ nanometres $(\mathrm{nm}))$. To date, biological scaffolds are the only scaffolds that have a resolution that mimics that of the native lung across all length scales. The bronchi TEM micrograph of a thin section of the mucous membrane of a small human bronchus shows a ciliated cell (CC) with cilia (C) and microvilli, a goblet cell (GC) with an apical mucous plug (MU), basal cell (BC), fibres and fibroblasts (FB) in connective tissue and macrophages (MP). The bronchi SEM micrograph of the epithelial surface shows ciliary tufts (C) and a mucous plug (MU) of a goblet cell in the process of extrusion. The distal lung TEM and SEM micrographs of the structure of the alveolar septum in human lungs show a septal fibroblast (FB), capillary endothelium (EN), alveolar epithelium (EP) and fibre strands (F). HE histology scale bars: $100 \mu \mathrm{m}$; bronchi TEM scale bar: $5 \mu \mathrm{m}$; bronchi SEM scale bar: $10 \mu \mathrm{m}$; distal lung TEM scale bar: $2 \mu \mathrm{m}$; distal lung SEM scale bar: $10 \mu \mathrm{m}$. Electron microscopy images reproduced and modified from $[129,130]$ with permission.

might therefore be an ideal solution as the biologically conducive nature of the ECM-derived scaffold material, such as sites for cell adhesion and organisational and differentiation cues, could be combined with synthetic materials and advanced manufacturing approaches to produce more reproducible products with tunable or controllable mechanical properties.

\section{Cell types and scaling-up cell culture methods}

In addition to identifying methods to reproducibly manufacturing suitable scaffolds for lung tissue engineering using either acellular or manufactured scaffolds, an additional challenge is in identifying cell sources and obtaining sufficient cell numbers. Ideally, autologous cells from the patient would be used for recellularising lung scaffolds in order to minimise post-transplantation immune complications and 
the need for immunosuppressive medications. However, ideal GMP-grade manufacturing methods for mass production of the different cells likely needed for lung bioengineering are currently not widely established.

Fully differentiated primary adult cells and/or autologous endogenous lung progenitor cells could be a potential source. However, when using such an approach, multiple cell types would likely need to be isolated from the patient, grown to sufficient numbers ex vivo and introduced into the scaffold in the correct locations in order to generate functional lung tissue.

Although our understanding of what a "fully differentiated" or adult cell type is in the lung is constantly evolving, the use of terminally differentiated cell types would not allow for repair of the lung following injury. Therefore, endogenous progenitor cells, known to participate in adult repair processes, may be a more reasonable approach. One potential approach for regenerating the multiple cell types in the lung could be to seed multiple progenitor cell populations into the lung scaffold with the ultimate goal of directing differentiation into the different cell types found in the adult lung. This would avoid the necessity of having to introduce each different cell type into the lung and direct it to its correct anatomical location. Two exciting recent reports demonstrated that sufficient numbers of endogenous epithelial progenitor cells could be sourced from a single patient and expanded ex vivo to cover either tracheal grafts or a large extent of whole acellular human lung lobes $[64,107]$. It is critical that these expansion methods are reliant on substances that are permissible for clinical use in humans [107]. Further development is needed to generate scalable methods using GMP-grade manufacturing approaches to ensure sufficient epithelial, endothelial or mesenchymal cell coverage. An additional limitation may also lie in identifying suitable endogenous progenitor cell populations from patients with existing lung disease. This may be challenging as there is emerging evidence that these cells are aberrant in chronic lung diseases [108-110]. However, this will be an interesting line of future research as previous reports indicate that the scaffold source influences cell behaviour more strongly than cell origin [26]. Thus, a normal scaffold may help revert the phenotype of cells obtained from diseased patients.

An alternative approach to endogenous progenitor cells is iPSCs. These are of particular interest as recent work has demonstrated that human iPSCs can be differentiated into cells expressing a distal pulmonary epithelial cell phenotype and seeded into acellular human lung scaffolds [59, 61]. Moreover, in patients with lung disease caused by known gene alterations, such as cystic fibrosis (CF), iPSCs derived from these patients could be gene-corrected prior to subsequent recellularisation [63, 111]. However, iPSCs also have several potential disadvantages: currently a patient skin biopsy is typically used to make iPSCs, but it has been shown that these cells partially retain the epigenetic memory of their tissue of origin [112]. This, while not yet explored in detail, could lead to limitations when differentiating iPSCs into specific lung lineages. Nonetheless, several studies have shown that iPSCs derived from fibroblasts can be used to derive cells containing phenotypic and functional markers of mature lung epithelial cell types $[61-63,113,114]$. Other studies have also examined the use of ESCs and found that these can be differentiated towards different adult epithelial phenotypes ex vivo $[60,66]$. Despite their promise, ESCs carry ethical concerns, and both ESCs and iPSCs have been shown to form teratomas $[115,116]$. Thus, both ESCs and iPSCs need to be further optimised and thoroughly investigated prior to clinical use.

Recent reports show promise for large-scale production and culture of cells using suspension culture (stirring) bioreactors and rotating wall bioreactors [61, 117], including techniques compliant with GMP and thus clinical use $[35,117-119]$. This could allow for translation of stem cell research to clinical and pre-clinical applications modelling a potential GMP workflow. However, large-scale production of cells will need to be optimised for each cell type. Despite these advances, it is evident that new methods that decrease cost and time will be needed for cost-effective and less labour-intensive large-scale production of cells for clinical use.

\section{Bioreactor strategies for lung bioengineering}

Although the study of perfusion and ventilation is more straightforward when using acellular, intact lungs, there are still relatively few reports that have addressed these parameters [131-133], in large part due to the limited availability of suitable lung bioreactors. Various bioreactor strategies have been developed in recent years for lung and airway bioengineering approaches or reconditioning of lungs that were rejected for transplantation [7, 134]. GHAEDI et al. [135] developed a rotating bioreactor that exposed cells seeded onto thin slices of acellular lung to air and liquid alternately, which resulted in alveolar epithelial cell expansion. For de- and recellularisation of human-sized lungs, GiLPIN et al. [50] developed a pressure-controlled apparatus where cell seeding was performed via gravitational force. A commercially available isolated lung perfusion system called the Organ Regenerative Control Acquisition bioreactor (Harvard Apparatus Regenerative Technologies, Holliston, MA, USA) has also been used by others for decellularisation $[33,34,136]$. Despite the advances made in the last few years with EVLP systems, the maximum amount of time that a healthy lung can be maintained ex vivo and transplanted is in the range 
of $6 \mathrm{~h}$ [137-139]. It is thought that bioengineering lungs ex vivo will require a far longer period of maturation time in a bioreactor prior to transplantation. An emerging approach for bioengineering of the upper airways, where mostly horizontal or upright bioreactors have been utilised before [140], is to use the human body as a bioreactor. For instance, DELAERE and co-workers [141, 142] bioengineered an allogeneic donor trachea first at the forearm of the recipient and then replaced the damaged trachea with the allograft. Attempts for de novo generation of organs also include the use of humanised animals such as pigs as bioreactors [143, 144]. Interestingly, a recent report using native porcine lungs in a cross-circulation model reported an ex vivo period of $36 \mathrm{~h}$, but transplantation was not evaluated as an outcome [5]. Regardless of the ex vivo approach, ensuring that the developing lung or airway tissue receives sufficient nutrients and is developing properly will be important to examine in more detail in future studies (table 1). Incorporation of real-time measurements such as glucose, lactate, electrolytes, $\mathrm{pH}$ and mechanical ventilation properties in addition to vascular resistance will be important to understand the necessary ex vivo culture time and help to design smarter bioreactor strategies.

\section{Regulatory and ethical implications for translating lung bioengineering approaches}

Despite the recent and exciting advances made in lung bioengineering, a number of significant regulatory, ethical and practical challenges will need to be addressed for any of these technologies to enter the clinic on a larger scale. Each set of challenges (e.g. classification of regenerative medicine products, approval of materials, use of stem cells, etc.) will be unique to the bioengineering approach used. When developing these new potential therapeutic approaches, it is critical that these translational concerns are addressed as early in the product development pipeline as possible. Establishment of regulatory frameworks and GMP standards for tissue-engineered products and the enforcement of these is necessary to prioritise patient safety $[145,146]$. Additionally, it remains completely unknown as to what evaluation criteria should be used for bioengineered lung tissue before the first-in-man clinical trials could be performed, but the use of parameters comparable to those used in EVLP may be a good first indication [147]. Moreover, the use of an appropriate large animal model that examines both shortand long-term outcomes will be necessary before these approaches are translated to the clinic. It will be critical for academic researchers, clinicians, industry and regulatory bodies to work with one another to establish these new frameworks.

To date, the majority of studies that have used human lungs for decellularisation have utilised lungs that do not meet the clinical criteria for transplantation or, alternatively, lungs from normal patients undergoing autopsy for non-lung-related death. Human tissue access for biomedical research differs significantly between different countries [148-150]. Therefore, if de- and recellularisation is to be realised on a larger scale and in the clinic, regulatory frameworks will need to be permissible for these technologies in each country. One potential unexplored source for generating acellular human lung scaffolds could be from DCD donors. DCD donors are used in many countries, but not all countries permit their usage due to ethical concerns. In most countries, DCD lungs are evaluated using EVLP prior to transplantation. However, a large portion of DCD donors are not used for transplant as they fail to reach the minimum criteria necessary for transplantation (primarily low blood gas values) after being evaluated ex vivo [151]. If all of these sources of human lung tissue can be used and bioengineering strategies can be designed to reproducibly generate functional lung tissue for transplantation, the biggest limiting factor will likely become the cost of manufacturing bioengineered lungs for all of the patients on waiting lists.

Although synthetic materials are not limited by these same ethical and regulatory restrictions with regard to identifying a suitable source, a major hurdle for the use of synthetic materials is the time and overall cost required for a material to receive European Medicines Agency or US Food and Drug Administration approval, which includes thorough characterisation of in vitro and in vivo material properties [152, 153]. Moreover, the regulation of stem cell and regenerative medicine products is a rapidly evolving area that varies greatly by country. In the last few years, countries such as Japan [154] have adopted new regulatory pathways that differ dramatically from the traditional paths to translation that have long-existed in most countries [150]. Therefore, the ability to conduct pre-clinical trials and ultimately the path to the clinic will be different in each country.

\section{Discussion and outlook}

Although significant progress has been made in bioengineering lung or airway tissue ex vivo with the ultimate goal of transplantation (table 2), most of the proof-of-concept studies for lung bioengineering have focused on endothelial and epithelial compartments. In order to generate functional lung tissue that will be able to function long term, the more than 40 different cell types and perhaps hundreds to thousands of different cellular subtypes will likely need to be recapitulated. However, it is currently not clear which of these cell types are essential to produce lung tissue that can minimally function in vivo. In one recent and innovative approach, the issue was raised as to whether all cells should be removed during 
decellularisation. Dorrello et al. [155] developed techniques to selectively decellularise the epithelium, but retain the endothelium. Such a technique could be employed either ex vivo or in vivo. It is known that an intact vascular network is critical for transplantation as well as for maintaining the blood-gas barrier and allowing for proper graft function, but also for supporting the regenerative cells [156]. Removing only epithelial cells and retaining the vascular endothelium might be an option to increase the success of re-seeding and implantation for certain patients. However, in chronic lung disease patients where the vasculature is severely damaged (e.g. pulmonary arterial hypertension (PAH)), this may not be a suitable approach.

One major intriguing question in the use of acellular lung scaffolds is the challenge of recellularising the interstitial spaces and the importance of innervation of smooth muscle cells. Will the cells seeded into decellularised constructs extravasate through the existing basement membranes? Will reseeded fibroblasts or smooth muscle cells simply "find their way" to the appropriate anatomical location if seeded through the airways or the vasculature? How critical is innervation, and how will this be achieved within the scaffold and integrated into the recipient nervous system? Although manufacturing techniques such as 3D printing might help overcome some of the challenges with regard to spatially depositing cells, there are other challenges such as incorporating and controlling multiple nozzles with each cell type and generating structures at length scales capable of gas exchange.

It will be important to more fully understand the behaviour of seeded cells into acellular, synthetic or hybrid scaffolds and any subsequent remodelling of the ECM or immune response. It is currently unclear how "clean" a scaffold needs to be for lung tissue engineering approaches. Evidence from pre-clinical studies [157] and clinical use of other acellular scaffolds indicates that the processing of acellular scaffolds can influence their immunogenicity $[46,158]$. In general, immune cells have not been introduced into any ex vivo bioengineering schemes; therefore, immunogenic responses would be limited to those that are a result of the recipient's immune system. Immune cells have been found to be able to induce pathological responses in fibroblasts seeded on acellular lung scaffolds, indicating their potential role in directing the fate of cells seeded on acellular scaffolds [159]. Interestingly, immune cells, such as macrophages, have recently been found to play a prominent role in directing normal alveolar regeneration in vivo [160]. Thus, the role of different immune cell populations in directing ex vivo regeneration and their potential role in regulating in vivo regeneration will be an interesting area of future investigation. Some tolerable amount of immunogenic proteins might help facilitate regeneration and maturation into functional tissue for transplantation during the ex vivo phase of maturation. Lung transplant recipients are currently placed on broad-spectrum immunosuppressive agents because a wide range of different immune cell populations (neutrophils, B-cells, T-cells, macrophages, etc.) have been implicated in lung transplant rejection, both acute and chronic rejection [30]. Whether or not this will be needed to the same extent for transplantation of a bioengineered lung is not yet known.

In addition, it is critical that future studies in the field more fully characterise and understand the potential functionality of bioengineered lung tissue (table 1). In clinical lung transplantation, patient demographics such as age, smoking history, absence of chest trauma and absence of malignancy are important criteria for selecting suitable donors, while functional criteria for donor lungs are $\mathrm{ABO}$ compatibility, clear chest radiograph, arterial oxygen tension $\left(\mathrm{PaO}_{2}\right)>300 \mathrm{mmHg}$ on inspiratory oxygen fraction $\left(\mathrm{FIO}_{2}\right) \quad 1.0 \%$ and positive end-expiratory pressure (PEEP) $5 \mathrm{cmH}_{2} \mathrm{O}$ [161]. For lungs reconditioned with EVLP, the current functional criteria differs between centres (e.g. Toronto, Lund or "OCS" (Organ Care System) protocol) [162]. Thus, one could envision that the minimum functional criteria for a bioengineered lung would be $\mathrm{PaO}_{2}>350-400 \mathrm{mmHg}$ on $\mathrm{FIO}_{2} 1.0 \%$ and PEEP $5 \mathrm{cmH}_{2} \mathrm{O}$, which is what is used for EVLP assessment [163]. Other standardised approaches for evaluation could be: blood gases from each bioengineered lobe, bronchoscopy, lactate dehydrogenase values, reactive oxygen species production, bronchoalveolar lavage analysis (of protein and inflammatory cytokines) and surfactant evaluations.

Although patent vasculature and gas exchange may be the most critical initial functions for evaluating whether a transplant could proceed, and have thus been the focus of previous studies [65], a bioengineered lung tissue and the cells within should ideally also be able to respond to the environment, meaning that other functions are likely necessary for longer-term functionality. Among these on the epithelial side are ciliary beating and clearance of inhaled particles and allergens, mucociliary clearance, and surfactant production. On the endothelial side, the ability of constructs to support events such as haemostasis and leukocyte extravasation in the context of lung injury will be important to explore in future studies. More broadly, any tissue-engineered construct should have the ability to respond appropriately to potential challenges and injuries, and to repair locally. Thus, how the recipient immune system may repopulate transplanted lung tissue remains almost entirely unexplored and may be incredibly important, especially given emerging evidence that the lung harbours haematopoietic progenitor cells and is a major site of platelet biogenesis in the body (up to $50 \%$ of total platelet production) [164]. Furthermore, it remains incompletely understood how recruited, monocyte-derived macrophages differ from tissue-resident 
macrophages in the lung [165], but they have been shown to be important for regeneration of the distal lung [160]. Whether or not these and other immune cells will need to be present or intentionally seeded in an ex vivo regeneration scheme remains unknown.

Currently, there are five major types of patients who receive the majority of lung transplants, i.e. chronic obstructive pulmonary disease (COPD), idiopathic pulmonary fibrosis (IPF), $\mathrm{PAH}, \mathrm{CF}$ and $\alpha_{1}$-antitrypsin deficiency (AATD) patients. In all chronic lung diseases (e.g. COPD, IPF and PAH), there are known defects in the endogenous lung progenitor cell populations. Thus, in the absence of gene correction or modulation with exogenous factors, it is unclear if these cell types can be used in a lung bioengineering scheme. iPSCs might therefore be considered the most promising source of cells for a clinically relevant scheme. However, in both CF [63, 166] and PAH [167], mutations are also found in iPSC-derived lung epithelial progenitor and endothelial cells, respectively. Recent techniques have shown that iPSC-derived lung epithelial progenitor cells from CF patients can be gene-corrected ex vivo [63]. Due to the differences in potential cell sources for patients with specific lung diseases, it is clear that the bioengineering approach will not be a "one size fits all" solution and will need to be modified for each of the different major groups of lung transplant patients, and perhaps for each patient if individual mutations need to be gene-corrected.

In addition to approaches that aim to generate single or double lungs, there could be clinical impact in reconstructing single lobes or only pieces of lung tissue. Although single- or double-lung transplant is standard, transplantation of single lobes is only performed in some centres, but could be beneficial for certain patient groups, such as COPD and AATD patients [168]. Furthermore, single-lobe transplant from an adult donor has been performed in paediatric patients where size matching is challenging with adult donors [169]. Thus, bioengineered single lobes could be of use. Clinical conditions where only a portion of the parenchyma or airway is affected (e.g. trauma, local bronchiectasis, tracheal collapse and nonsmall cell lung cancer) could benefit from these approaches. Techniques to manufacture alveolar-like structures [82, 85, 86, 127], tracheal supports [99, 100] and replacements [146] have all been developed recently. Furthermore, there has been work on the development of biomaterials that can serve as artificial pleuras for diseases and acute conditions that affect the visceral pleura (e.g. pneumothorax and mesothelioma) $[170,171]$. Thus, there may be potential clinical impact for partial reconstruction or replacement of lung tissue with tissue-engineered products in patients where only certain regions of the lung are damaged.

The pursuit of lung bioengineering approaches for regenerating lung tissue for transplantation has opened new opportunities for ex vivo modelling of different lung diseases. Although there has been less research on the use of synthetic materials in modelling lung disease, this is an emerging area of research with great potential to help model new aspects of lung disease that current models cannot address. Acellular lungs derived from patients with chronic lung disease more completely recapitulate the clinical heterogeneity and more faithfully mimic the clinical disease. In the pursuit of bioengineering lung tissue for transplantation, the approaches developed can also be used for performing drug screens, replacement of animal models, and better understanding of different lung diseases and regeneration. However, the majority of studies have been performed under simplified conditions that do not completely recapitulate the in vivo scenario. Future incorporation of immune cells as well as physiological parameters such as ventilation, perfusion and control of oxygen levels should be examined.

Tissue engineering of (complex) organs was once thought to be restricted to the realm of science fiction. However, exciting recent advances in the tissue engineering field are supportive of the idea that these technologies may indeed one day lead to therapies for patients with devastating and debilitating lung diseases. The recent significant advances made in lung tissue engineering have been largely due to the collaboration between biologists, chemists, material scientists, clinicians and engineers in both academia and industry; the realisation of lung tissue and airway engineering technologies in the clinic will be contingent on the continued evolution and successful integration of these fields.

Acknowledgements: The authors thank all the members of the Lung Bioengineering and Regeneration Laboratory (Lund University, Lund, Sweden) for helpful discussions throughout the manuscript preparation and for critical reading of the final manuscript. The authors are grateful to Ewald Weibel (University of Bern, Bern, Switzerland) for insightful discussions and electron microscopy images, and Scott Randell (UNC School of Medicine, Chapel Hill, NC, USA) for histological images. We also thank Alice Caiado (London College of Communication, University of Arts London, London, UK) for providing some of the lung graphics within the manuscript.

Author contributions: All authors were involved in the writing, editing and approval of the final manuscript.

Conflict of interest: D.E. Wagner reports grants from Knut and Alice Wallenberg Foundation and German Lung Center, during the conduct of the study; and in addition has a patent (WO2014169111 A1) pending.

Support statement: This work was funded by Wallenberg Molecular Medicine Fellowships (D.E. Wagner and S. Lindstedt) from the Knut and Alice Wallenberg Foundation, and a Helmholtz Munich Postdoctoral Fellowship (D.E. Wagner). Funding information for this article has been deposited with the Crossref Funder Registry. 


\section{References}

1 Gibson GJ, Loddenkemper R, Sibille Y, et al., eds. The economic burden of lung disease. In: European Lung White Book. 2nd Edn. Sheffield, European Respiratory Society, 2013; pp. 16-27.

2 European Commission. Journalist Workshop on Organ Donation and Transplantation. Recent Facts \& Figures. 2014. http://ec.europa.eu/health/sites/health/files/blood_tissues_organs/docs/ev_20141126_factsfigures_en.pdf Date last accessed: June 12,2018.

3 Yusen RD, Edwards LB, Kucheryavaya AY, et al. The Registry of the International Society for Heart and Lung Transplantation: Thirty-second Official Adult Lung and Heart-Lung Transplantation Report 2015; Focus Theme: Early Graft Failure. J Heart Lung Transplant 2015; 34: 1264-1277.

4 Fisher A, Andreasson A, Chrysos A, et al. An observational study of Donor Ex Vivo Lung Perfusion in UK lung transplantation: DEVELOP-UK. Health Technol Assess 2016; 20: 1-276.

5 O'Neill JD, Guenthart BA, Kim J, et al. Cross-circulation for extracorporeal support and recovery of the lung. Nat Biomed Eng 2017; 1: 0037.

6 Cypel M, Yeung JC, Liu M, et al. Normothermic ex vivo lung perfusion in clinical lung transplantation. $N$ Engl J Med 2011; 364: 1431-1440.

7 Ingemansson R, Eyjolfsson A, Mared L, et al. Clinical transplantation of initially rejected donor lungs after reconditioning ex vivo. Ann Thorac Surg 2009; 87: 255-260.

8 Machuca TN, Mercier O, Collaud S, et al. Lung transplantation with donation after circulatory determination of death donors and the impact of ex vivo lung perfusion. Am J Transplant 2015; 15: 993-1002.

9 Shaver CM, Diamond JM, Schrepfer S, et al. Optimization of oxygenation during ex vivo lung perfusion - best basic science article in 2017. J Heart Lung Transplant 2018; 37: 800-802.

10 Franks TJ, Colby TV, Travis WD, et al. Resident cellular components of the human lung: current knowledge and goals for research on cell phenotyping and function. Proc Am Thorac Soc 2008; 5: 763-766.

11 Burgstaller G, Oehrle B, Gerckens M, et al. The instructive extracellular matrix of the lung: basic composition and alterations in chronic lung disease. Eur Respir J 2017; 50: 1601805.

12 Langer R, Vacanti JP. Tissue engineering. Science 1993; 260: 920-926.

13 Atala A, Bauer SB, Soker S, et al. Tissue-engineered autologous bladders for patients needing cystoplasty. Lancet 2006; 367: 1241-1246.

14 Shin'oka T, Matsumura G, Hibino N, et al. Midterm clinical result of tissue-engineered vascular autografts seeded with autologous bone marrow cells. J Thorac Cardiovasc Surg 2005; 129: 1330-1338.

15 Wagner DE, Bonvillain RW, Jensen T, et al. Can stem cells be used to generate new lungs? Ex vivo lung bioengineering with decellularized whole lung scaffolds. Respirology 2013; 18: 895-911.

16 Gilpin SE, Charest JM, Ren X, et al. Bioengineering lungs for transplantation. Thorac Surg Clin 2016; 26: 163-171.

17 Calle EA, Leiby KL, Raredon MB, et al. Lung regeneration: steps toward clinical implementation and use. Curr Opin Anaesthesiol 2017; 30: 23-29.

18 Crapo PM, Gilbert TW, Badylak SF. An overview of tissue and whole organ decellularization processes. Biomaterials 2011; 32: 3233-3243.

19 Badylak SF, Taylor D, Uygun K. Whole-organ tissue engineering: decellularization and recellularization of three-dimensional matrix scaffolds. Annu Rev Biomed Eng 2011; 13: 27-53.

20 Freytes DO, Martin J, Velankar SS, et al. Preparation and rheological characterization of a gel form of the porcine urinary bladder matrix. Biomaterials 2008; 29: 1630-1637.

21 Wagner DE, Bonenfant NR, Parsons CS, et al. Comparative decellularization and recellularization of normal versus emphysematous human lungs. Biomaterials 2014; 35: 3281-3297.

22 Fischer SN, Johnson JK, Baran $\mathrm{CP}$, et al. Organ-derived coatings on electrospun nanofibers as ex vivo microenvironments. Biomaterials 2011; 32: 538-546.

23 O'Neill JD, Anfang R, Anandappa A, et al. Decellularization of human and porcine lung tissues for pulmonary tissue engineering. Ann Thorac Surg 2013; 96: 1046-1055.

24 Wagner DE, Bonenfant NR, Sokocevic D, et al. Three-dimensional scaffolds of acellular human and porcine lungs for high throughput studies of lung disease and regeneration. Biomaterials 2014; 35: 2664-2679.

25 Platz J, Bonenfant NR, Uhl FE, et al. Comparative decellularization and recellularization of wild-type and alpha 1,3 galactosyltransferase knockout pig lungs: a model for ex vivo xenogeneic lung bioengineering and transplantation. Tissue Eng Part C Methods 2016; 22: 725-739.

26 Parker MW, Rossi D, Peterson M, et al. Fibrotic extracellular matrix activates a profibrotic positive feedback loop. $J$ Clin Invest 2014; 124: 1622-1635.

27 Godin LM, Sandri BJ, Wagner DE, et al. Decreased laminin expression by human lung epithelial cells and fibroblasts cultured in acellular lung scaffolds from aged mice. PLoS One 2016; 11: e0150966.

28 Gilpin SE, Li Q, Evangelista-Leite D, et al. Fibrillin-2 and Tenascin-C bridge the age gap in lung epithelial regeneration. Biomaterials 2017; 140: 212-219.

29 Arenas-Herrera JE, Ko IK, Atala A, et al. Decellularization for whole organ bioengineering. Biomed Mater 2013; 8: 014106.

30 Shaver CM, Ware LB. Primary graft dysfunction: pathophysiology to guide new preventive therapies. Exp Rev Respir Med 2017; 11: 119-128.

31 Mizota T, Miyao M, Yamada T, et al. Graft dysfunction immediately after reperfusion predicts short-term outcomes in living-donor lobar lung transplantation but not in cadaveric lung transplantation. Int Cardiovasc Thorac Surg 2016; 22: 314-320.

32 Bonvillain RW, Danchuk S, Sullivan DE, et al. A nonhuman primate model of lung regeneration: detergent-mediated decellularization and initial in vitro recellularization with mesenchymal stem cells. Tissue Eng Part A 2012; 18: 2437-2452.

33 Nichols JE, Niles J, Riddle M, et al. Production and assessment of decellularized pig and human lung scaffolds. Tissue Eng Part A 2013; 19: 2045-2062.

34 Price AP, Godin LM, Domek A, et al. Automated decellularization of intact, human-sized lungs for tissue engineering. Tissue Eng Part C Methods 2015; 21: 94-103.

35 Zhou H, Kitano K, Ren X, et al. Bioengineering human lung grafts on porcine matrix. Ann Surg 2017; 267: 590-598. 
Balestrini JL, Gard AL, Gerhold KA, et al. Comparative biology of decellularized lung matrix: implications of species mismatch in regenerative medicine. Biomaterials 2016; 102: 220-230.

Barnard JB, Davies O, Curry P, et al. Size matching in lung transplantation: an evidence-based review. J Heart Lung Transplant 2013; 32: 849-860.

Niu D, Wei H-J, Lin L, et al. Inactivation of porcine endogenous retrovirus in pigs using CRISPR-Cas9. Science 2017; 357: 1303-1307.

Cypel M, Rubacha M, Yeung J, et al. Normothermic ex vivo perfusion prevents lung injury compared to extended cold preservation for transplantation. Am J Transplant 2009; 9: 2262-2269.

Cypel M, Yeung JC, Hirayama S, et al. Technique for prolonged normothermic ex vivo lung perfusion. J Heart Lung Transplant 2008; 27: 1319-1325.

Steen S, Sjoberg T, Pierre L, et al. Transplantation of lungs from a non-heart-beating donor. Lancet 2001; 357 825-829.

Bonenfant NR, Sokocevic D, Wagner DE, et al. The effects of storage and sterilization on de-cellularized and re-cellularized whole lung. Biomaterials 2013; 34: 3231-3245.

Matuska AM, McFetridge PS. The effect of terminal sterilization on structural and biophysical properties of a decellularized collagen-based scaffold; implications for stem cell adhesion. J Biomed Mater Res B Appl Biomater 2015; 103: 397-406.

Hodde J, Janis A, Ernst D, et al. Effects of sterilization on an extracellular matrix scaffold: part I. Composition and matrix architecture. J Mater Sci Mater Med 2007; 18: 537-543.

Balestrini JL, Liu A, Gard AL, et al. Sterilization of lung matrices by supercritical carbon dioxide. Tissue Eng Part C Methods 2016; 22: 260-269.

Brown BN, Badylak SF. Extracellular matrix as an inductive scaffold for functional tissue reconstruction. Transl Res 2014; 163: 268-285.

Wolf MT, Vodovotz Y, Tottey S, et al. Predicting in vivo responses to biomaterials via combined in vitro and in silico analysis. Tissue Eng Part C Methods 2015; 21: 148-159.

Petersen TH, Calle EA, Zhao L, et al. Tissue-engineered lungs for in vivo implantation. Science 2010; 329: 538-541. Booth AJ, Hadley R, Cornett AM, et al. Acellular normal and fibrotic human lung matrices as a culture system for in vitro investigation. Am J Respir Crit Care Med 2012; 186: 866-876.

Gilpin SE, Guyette JP, Gonzalez G, et al. Perfusion decellularization of human and porcine lungs: bringing the matrix to clinical scale. J Heart Lung Transplant 2014; 33: 298-308.

Gilpin SE, Ren X, Okamoto T, et al. Enhanced lung epithelial specification of human induced pluripotent stem cells on decellularized lung matrix. Ann Thorac Surg 2014; 98: 1721-1729.

Wallis JM, Borg ZD, Daly AB, et al. Comparative assessment of detergent-based protocols for mouse lung de-cellularization and re-cellularization. Tissue Eng Part C Methods 2012; 18: 420-432.

Petersen TH, Calle EA, Colehour MB, et al. Matrix composition and mechanics of decellularized lung scaffolds. Cells Tissues Organs 2012; 195: 222-231.

Brown BN, Valentin JE, Stewart-Akers AM, et al. Macrophage phenotype and remodeling outcomes in response to biologic scaffolds with and without a cellular component. Biomaterials 2009; 30: 1482-1491.

Badylak SF, Gilbert TW. Immune response to biologic scaffold materials. Semin Immunol 2008; 20: 109-116.

Zvarova B, Uhl FE, Uriarte JJ, et al. Residual detergent detection method for nondestructive cytocompatibility evaluation of decellularized whole lung scaffolds. Tissue Eng Part C Methods 2016; 22: 418-428.

Kawecki M, Łabuś W, Klama-Baryla A, et al. A review of decellurization methods caused by an urgent need for quality control of cell-free extracellular matrix' scaffolds and their role in regenerative medicine. J Biomed Mater Res B Appl Biomater 2018; 106: 909-923.

Chen Y-W, Huang SX, de Carvalho ALRT, et al. A three-dimensional model of human lung development and disease from pluripotent stem cells. Nat Cell Biol 2017; 19: 542-549.

Huang SXL, Islam MN, O'Neill J, et al. Efficient generation of lung and airway epithelial cells from human pluripotent stem cells. Nat Biotechnol 2014; 32: 84-91.

Longmire TA, Ikonomou L, Hawkins F, et al. Efficient derivation of purified lung and thyroid progenitors from embryonic stem cells. Cell Stem Cell 2012; 10: 398-411.

Ghaedi M, Calle EA, Mendez JJ, et al. Human iPS cell-derived alveolar epithelium repopulates lung extracellular matrix. J Clin Invest 2013; 123: 4950-4962.

Wong AP, Bear CE, Chin S, et al. Directed differentiation of human pluripotent stem cells into mature airway epithelia expressing functional CFTR protein. Nat Biotechnol 2012; 30: 876-882.

McCauley KB, Hawkins F, Serra M, et al. Efficient derivation of functional human airway epithelium from pluripotent stem cells via temporal regulation of Wnt signaling. Cell Stem Cell 2017; 20: 844-857.

Gilpin SE, Charest JM, Ren X, et al. Regenerative potential of human airway stem cells in lung epithelial engineering. Biomaterials 2016; 108: 111-119.

Ren X, Moser PT, Gilpin SE, et al. Engineering pulmonary vasculature in decellularized rat and human lungs. Nat Biotechnol 2015; 33: 1097-1102.

S, Ermini L, Ackerley C, et al. Acellular lung scaffolds direct differentiation of endoderm to functional airway epithelial cells: requirement of matrix-bound HS proteoglycans. Stem Cell Reports 2015; 4: 419-430.

Ghaedi M, Le AV, Hatachi G, et al. Bioengineered lungs generated from human iPSCs-derived epithelial cells on native extracellular matrix. J Tissue Eng Regen Med 2018; 12: e1623-e1635.

Ott HC, Clippinger B, Conrad C, et al. Regeneration and orthotopic transplantation of a bioartificial lung. Nat Med 2010; 16: 927-933.

Song JJ, Kim SS, Liu Z, et al. Enhanced in vivo function of bioartificial lungs in rats. Ann Thorac Surg 2011; 92: 998-1005.

Seif-Naraghi SB, Horn D, Schup-Magoffin PA, et al. Patient-to-patient variability in autologous pericardial matrix scaffolds for cardiac repair. J Cardiovasc Transl Res 2011; 4: 545-556.

Londono R, Dziki JL, Haljasmaa E, et al. The effect of cell debris within biologic scaffolds upon the macrophage response. J Biomed Mater Res A 2017; 105: 2109-2118.

Crowley C, Klanrit P, Butler CR, et al. Surface modification of a POSS-nanocomposite material to enhance cellular integration of a synthetic bioscaffold. Biomaterials 2016; 83: 283-293. 
Hinderer S, Schesny M, Bayrak A, et al. Engineering of fibrillar decorin matrices for a tissue-engineered trachea. Biomaterials 2012; 33: 5259-5266.

Crowley C, Birchall M, Seifalian AM. Trachea transplantation: from laboratory to patient. J Tissue Eng Regen Med 2015; 9: 357-367.

Jungebluth P, Alici E, Baiguera S, et al. Tracheobronchial transplantation with a stem-cell-seeded bioartificial nanocomposite: a proof-of-concept study. Lancet 2011; 378: 1997-2004.

Teoh GZ, Crowley C, Birchall MA, et al. Development of resorbable nanocomposite tracheal and bronchial scaffolds for paediatric applications. Br J Surg 2015; 102: e140-e150.

Chang JW, Park SA, Park JK, et al. Tissue-engineered tracheal reconstruction using three-dimensionally printed artificial tracheal graft: preliminary report. Artif Organs 2014; 38: E95-E105.

Jungebluth P, Haag JC, Sjoqvist S, et al. Tracheal tissue engineering in rats. Nat Protoc 2014; 9: 2164-2179.

Cortiella J, Nichols JE, Kojima K, et al. Tissue-engineered lung: an in vivo and in vitro comparison of polyglycolic acid and pluronic F-127 hydrogel/somatic lung progenitor cell constructs to support tissue growth. Tissue Eng 2006; 12: 1213-1225.

Mondrinos MJ, Koutzaki S, Jiwanmall E, et al. Engineering three-dimensional pulmonary tissue constructs. Tissue Eng 2006; 12: 717-728.

Weibel ER. Lung morphometry: the link between structure and function. Cell Tissue Res 2017; 367: 413-426.

Ling TY, Liu YL, Huang YK, et al. Differentiation of lung stem/progenitor cells into alveolar pneumocytes and induction of angiogenesis within a 3D gelatin-microbubble scaffold. Biomaterials 2014; 35: 5660-5669.

Andrade CF, Wong AP, Waddell TK, et al. Cell-based tissue engineering for lung regeneration. Am J Physiol Lung Cell Mol Physiol 2007; 292: L510-L518.

Singh D, Zo SM, Kumar A, et al. Engineering three-dimensional macroporous hydroxyethyl methacrylate-alginategelatin cryogel for growth and proliferation of lung epithelial cells. J Biomater Sci Polym Ed 2013; 24: 1343-1359.

Lewis KJR, Hall JK, Kiyotake EA, et al. Epithelial-mesenchymal crosstalk influences cellular behavior in a 3D alveolus-fibroblast model system. Biomaterials 2018; 155: 124-134.

Lewis KJR, Tibbitt MW, Zhao Y, et al. In vitro model alveoli from photodegradable microsphere templates. Biomater Sci 2015; 3: 821-832.

Wilkinson DC, Alva-Ornelas JA, Sucre JM, et al. Development of a three-dimensional bioengineering technology to generate lung tissue for personalized disease modeling. Stem Cells Transl Med 2017; 6: 622-633.

Nematollahi Z, Tafazzoli-Shadpour M, Zamanian A, et al. Fabrication of chitosan silk-based tracheal scaffold using freeze-casting method. Iran Biomed J 2017; 21: 228-239.

Lee VK, Kim DY, Ngo H, et al. Creating perfused functional vascular channels using 3D bio-printing technology. Biomaterials 2014; 35: 8092-8102.

Ercolani E, Del Gaudio C, Bianco A. Vascular tissue engineering of small-diameter blood vessels: reviewing the electrospinning approach. J Tissue Eng Regen Med 2015; 9: 861-888.

Powell HM, Boyce ST. Engineered human skin fabricated using electrospun collagen-PCL blends: morphogenesis and mechanical properties. Tissue Eng Part A 2009; 15: 2177-2187.

Bhattacharjee T, Zehnder SM, Rowe KG, et al. Writing in the granular gel medium. Sci Adv 2015; 1: e1500655.

Hinton TJ, Jallerat Q, Palchesko RN, et al. Three-dimensional printing of complex biological structures by freeform reversible embedding of suspended hydrogels. Sci Adv 2015; 1: e1500758.

Feinberg AW, Miller JS. Progress in three-dimensional bioprinting. MRS Bull 2017; 42: 557-562.

Zhu $\mathrm{W}, \mathrm{Qu} \mathrm{X}$, Zhu J, et al. Direct 3D bioprinting of prevascularized tissue constructs with complex microarchitecture. Biomaterials 2017; 124: 106-115.

Kolesky DB, Homan KA, Skylar-Scott MA, et al. Three-dimensional bioprinting of thick vascularized tissues. Proc Natl Acad Sci USA 2016; 113: 3179-3184.

Hansen CJ, Saksena R, Kolesky DB, et al. High-throughput printing via microvascular multinozzle arrays. Adv Mater 2013; 25: 96-102.

Pratt AB, Weber FE, Schmoekel HG, et al. Synthetic extracellular matrices for in situ tissue engineering. Biotechnol Bioeng 2004; 86: 27-36.

Morrison RJ, Hollister SJ, Niedner MF, et al. Mitigation of tracheobronchomalacia with 3D-printed personalized medical devices in pediatric patients. Sci Transl Med 2015; 7: $285 \mathrm{ra64.}$

Zopf DA, Hollister SJ, Nelson ME, et al. Bioresorbable airway splint created with a three-dimensional printer. N Engl J Med 2013; 368: 2043-2045.

Taniguchi D, Matsumoto K, Tsuchiya T, et al. Scaffold-free trachea regeneration by tissue engineering with bio-3D printing. Interact Cardiovasc Thorac Surg 2018; 26: 745-775.

Cubo N, Garcia M, Del Canizo JF, et al. 3D bioprinting of functional human skin: production and in vivo analysis. Biofabrication 2016; 9: 015006.

Cui X, Breitenkamp K, Finn MG, et al. Direct human cartilage repair using three-dimensional bioprinting technology. Tissue Eng Part A 2012; 18: 1304-1312.

Duan B, Hockaday LA, Kang $\mathrm{KH}$, et al. 3D bioprinting of heterogeneous aortic valve conduits with alginate/ gelatin hydrogels. J Biomed Mater Res A 2013; 101: 1255-1264.

Norotte C, Marga FS, Niklason LE, et al. Scaffold-free vascular tissue engineering using bioprinting. Biomaterials 2009; 30: 5910-5917.

Polak DJ. The use of stem cells to repair the injured lung. Br Med Bull 2011; 99: 189-197.

J Respir Crit Care Med 2016; 194: 156-168.

Naikawadi RP, Disayabutr S, Mallavia B, et al. Telomere dysfunction in alveolar epithelial cells causes lung remodeling and fibrosis. JCI Insight 2016; 1: e86704.

Shaykhiev R, Wang R, Zwick RK, et al. Airway basal cells of healthy smokers express an embryonic stem cell signature relevant to lung cancer. Stem Cells 2013; 31: 1992-2002.

Gentzsch M, Boyles SE, Cheluvaraju C, et al. Pharmacological rescue of conditionally reprogrammed cystic fibrosis bronchial epithelial cells. Am J Respir Cell Mol Biol 2017; 56: 568-574.

AL, Menon T, Parker GS, et al. Functional gene correction for cystic fibrosis in lung epithelial cells generated from patient iPSCs. Cell Rep 2015; 12: 1385-1390. 
Kim K, Doi A, Wen B, et al. Epigenetic memory in induced pluripotent stem cells. Nature 2010; 467: 285-290. Firth AL, Dargitz CT, Qualls SJ, et al. Generation of multiciliated cells in functional airway epithelia from human induced pluripotent stem cells. Proc Natl Acad Sci USA 2014; 111: E1723-E1730.

Hawkins F, Kramer P, Jacob A, et al. Prospective isolation of NKX2
derived from pluripotent stem cells. J Clin Invest 2017; 127: 2277-2294.

Takahashi K, Yamanaka S. Induction of pluripotent stem cells from mouse embryonic and adult fibroblast cultures by defined factors. Cell 2006; 126: 663-676.

Thomson JA, Itskovitz-Eldor J, Shapiro SS, et al. Embryonic stem cell lines derived from human blastocysts. Science 1998; 282: 1145-1147.

Raredon MSB, Ghaedi M, Calle EA, et al. A rotating bioreactor for scalable culture and differentiation of respiratory epithelium. Cell Med 2015; 7: 109-121.

Kempf H, Kropp C, Olmer R, et al. Cardiac differentiation of human pluripotent stem cells in scalable suspension culture. Nat Protoc 2015; 10: 1345-1361.

Olmer R, Lange A, Selzer S, et al. Suspension culture of human pluripotent stem cells in controlled, stirred bioreactors. Tissue Eng Part C Methods 2012; 18: 772-784.

Lin YM, Boccaccini AR, Polak JM, et al. Biocompatibility of poly-DL-lactic acid (PDLLA) for lung tissue engineering. J Biomater Appl 2006; 21: 109-118.

Kuttan R, Spall RD, Duhamel RC, et al. Preparation and composition of alveolar extracellular matrix and incorporated basement membrane. Lung 1981; 159: 333-345.

Lwebuga-Mukasa JS, Ingbar DH, Madri JA. Repopulation of a human alveolar matrix by adult rat type II pneumocytes in vitro. A novel system for type II pneumocyte culture. Exp Cell Res 1986; 162: 423-435.

Shamis Y, Hasson E, Soroker A, et al. Organ-specific scaffolds for in vitro expansion, differentiation, and organization of primary lung cells. Tissue Eng Part C Methods 2011; 17: 861-870.

Sokocevic D, Bonenfant NR, Wagner DE, et al. The effect of age and emphysematous and fibrotic injury on the re-cellularization of de-cellularized lungs. Biomaterials 2013; 34: 3256-3269.

Pouliot RA, Link PA, Mikhaiel NS, et al. Development and characterization of a naturally derived lung extracellular matrix hydrogel. J Biomed Mater Res A 2016; 104: 1922-1935.

Mondrinos MJ, Koutzaki SH, Poblete HM, et al. In vivo pulmonary tissue engineering: contribution of donor-derived endothelial cells to construct vascularization. Tissue Eng Part A 2008; 14: 361-368.

Zhang W-J, Lin Q-X, Zhang Y, et al. The reconstruction of lung alveolus-like structure in collagen-matrigel/ microcapsules scaffolds in vitro. J Cell Mol Med 2011; 15: 1878-1886.

Ghorbani F, Moradi L, Shadmehr MB, et al. In-vivo characterization of a 3D hybrid scaffold based on PCL/ decellularized aorta for tracheal tissue engineering. Mater Sci Eng C Mater Biol Appl 2017; 81: 74-83.

Weibel ER. Lung cell biology. In: AP Fishman, ed. Handbook of Physiology. Section 3: The Respiratory System. Bethesda, American Physiological Society, 2011; pp. 47-91.

Hsia CC, Hyde DM, Weibel ER. Lung structure and the intrinsic challenges of gas exchange. Compr Physiol 2016; 6: 827-895.

Stabler CT, Caires LC, Mondrinos MJ, et al. Enhanced re-endothelialization of decellularized rat lungs. Tissue Eng Part C Methods 2016; 22: 439-450.

Scarritt ME, Pashos NC, Motherwell JM, et al. Re-endothelialization of rat lung scaffolds through passive, gravity-driven seeding of segment-specific pulmonary endothelial cells. J Tissue Eng Regen Med 2018; 12: e786-e806.

Scarritt ME, Bonvillain RW, Burkett BJ, et al. Hypertensive rat lungs retain hallmarks of vascular disease upon decellularization but support the growth of mesenchymal stem cells. Tissue Eng Part A 2014; 20: 1426-1443.

Panoskaltsis-Mortari A. Bioreactor development for lung tissue engineering. Curr Transplant Rep 2015; 2: 90-97.

Ghaedi M, Mendez JJ, Bove PF, et al. Alveolar epithelial differentiation of human induced pluripotent stem cells in a rotating bioreactor. Biomaterials 2014; 35: 699-710.

Khalpey Z, Qu N, Hemphill C, et al. Rapid porcine lung decellularization using a novel organ regenerative control acquisition bioreactor. ASAIO J 2015; 61: 71-77.

Warnecke G, Moradiellos J, Tudorache I, et al. Normothermic perfusion of donor lungs for preservation and assessment with the Organ Care System Lung before bilateral transplantation: a pilot study of 12 patients. Lancet 2012; 380: 1851-1858.

Spratt JR, Mattison LM, Iaizzo PA, et al. Lung transplantation from DCD donors after prolonged normothermic portable EVLP. J Heart Lung Transplant 2017; 36: S312.

Spratt JR, Mattison LM, Kerns NK, et al. Prolonged preservation and evaluation of human lungs with portable normothermic EVLP. J Heart Lung Transplant 2018; 37: S242.

Regen Med 2010; 4: 619-627.

Delaere P, Vranckx J, Verleden G, et al. Tracheal allotransplantation after withdrawal of immunosuppressive therapy. N Engl J Med 2010; 362: 138-145.

N Engl J Med 2014; 370: 1568-1570.

Kemter E, Wolf E. Pigs pave a way to de novo formation of functional human kidneys. Proc Natl Acad Sci USA 2015; 112: 12905-12906.

Garry MG, Garry DJ. Humanized organs in gene-edited animals. Regen Med 2016; 11: 617-619.

Elliott MJ, Butler CR, Varanou-Jenkins A, et al. Tracheal replacement therapy with a stem cell-seeded graft: lessons from compassionate use application of a GMP-compliant tissue-engineered medicine. Stem Cells Transl Med 2017; 6: 1458-1464.

Etienne H, Fabre D, Gomez Caro A, et al. Tracheal replacement. Eur Respir J 2018; 51: 1702211.

Ikonomou L, Freishtat RJ, Wagner DE, et al. The global emergence of unregulated stem cell treatments for respiratory diseases. professional societies need to act. Ann Am Thorac Soc 2016; 13: 1205-1207.

Anderson R, O'Hare M, Balls M, et al. The availability of human tissue for biomedical research: the report and recommendations of the ECVAM workshop 32. Altern Lab Anim 1998; 26: 763-777. 
Beier K, Schnorrer S, Hoppe N, et al., eds. The Ethical and Legal Regulation of Human Tissue and Biobank Research in Europe. Proceedings of the Tiss.EU Project. Göttingen,Universitätsverlag Göttingen, 2011.

Berger AC, Beachy SH, Olsen S, et al. Stem Cell Therapies: Opportunities for Ensuring the Quality and Safety of Clinical Offerings: Summary of a Joint Workshop by the Institute of Medicine, the National Academy of Sciences, and the International Society for Stem Cell Research. Washington, The National Academies Press, 2014. Machuca TN, Mercier O, Collaud S, et al. Outcomes of lung transplantation using donation after cardiac death donors: should we use ex vivo lung perfusion? J Heart Lung Transplant 2014; 33: S272.

Mao AS, Mooney DJ. Regenerative medicine: current therapies and future directions. Proc Natl Acad Sci USA 2015; 112: 14452-14459.

Kaplan AV, Baim DS, Smith JJ, et al. Medical device development: from prototype to regulatory approval. Circulation 2004; 109: 3068-3072.

Konomi K, Tobita M, Kimura K, et al. New Japanese initiatives on stem cell therapies. Cell Stem Cell 2015; 16: 350-352.

Dorrello NV, Guenthart BA, O’Neill JD, et al. Functional vascularized lung grafts for lung bioengineering. Sci Adv 2017; 3: e1700521.

Chang WG, Niklason LE. A short discourse on vascular tissue engineering. NPJ Regen Med 2017; 2: 7.

Fernandez-Moure JS, Van Eps JL, Rhudy JR, et al. Porcine acellular lung matrix for wound healing and abdominal wall reconstruction: a pilot study. J Tissue Eng 2016; 7: 2041731415626018. decellularization. Tissue Eng Part C Methods 2014; 20: 1028-1036.

Zhou Y, Peng H, Sun H, et al. Chitinase 3-like 1 suppresses injury and promotes fibroproliferative responses in mammalian lung fibrosis. Science Transl Med 2014; 6: 240ra76.

Lechner AJ, Driver IH, Lee J, et al. Recruited monocytes and type 2 immunity promote lung regeneration following pneumonectomy. Cell Stem Cell 2017; 21: 120-134.

Rosengard BR, Feng S, Alfrey EJ, et al. Report of the Crystal City meeting to maximize the use of organs recovered from the cadaver donor. Am J Transplant 2002; 2: 701-711.

Raemdonck D, Neyrinck A, Cypel M, et al. Ex-vivo lung perfusion. Transplant Int 2015; 28: 643-656.

Lindstedt S, Eyjolfsson A, Koul B, et al. How to recondition ex vivo initially rejected donor lungs for clinical transplantation: clinical experience from Lund University Hospital. J Transplant 2011; 2011: 754383.

Lefrançais E, Ortiz-Muñoz G, Caudrillier A, et al. The lung is a site of platelet biogenesis and a reservoir for haematopoietic progenitors. Nature 2017; 544: 105-109.

Morales-Nebreda L, Misharin AV, Perlman H, et al. The heterogeneity of lung macrophages in the susceptibility to disease. Eur Respir Rev 2015; 24: 505-509.

Fakhro M, Ingemansson R, Skog I, et al. 25-year follow-up after lung transplantation at Lund University Hospital in Sweden: superior results obtained for patients with cystic fibrosis. Interact Cardiovasc Thorac Surg 2016; 23: 65-73.

Sa S, Gu M, Chappell J, et al. Induced pluripotent stem cell model of pulmonary arterial hypertension reveals novel gene expression and patient specificity. Am J Respir Crit Care Med 2017; 195: 930-941.

Sato M, Okada Y, Oto T, et al. Registry of the Japanese Society of Lung and Heart-Lung Transplantation: official Japanese lung transplantation report, 2014. Gen Thorac Cardiovasc Surg 2014; 62: 594-601. venoocclusive disease. Ann Thorac Surg 2013; 95: 689-691. Wagner DE, Fenn SL, Bonenfant NR, et al. Design and synthesis of an artificial pulmonary pleura for high throughput studies in acellular human lungs. Cell Mol Bioeng 2014; 7: 184-195.

Fenn SL, Charron PN, Oldinski RA. Anticancer therapeutic alginate-based tissue sealants for lung repair. ACS Appl Mater Interfaces 2017; 9: 23409-23419. 